\title{
水热合成镍铜复合磷化物及其电催化析氢与肼氧化性能
}

\author{
李 兆 ${ }^{1}$, 孙强强 ${ }^{2}$, 陈索倩 ${ }^{2}$, 周春生 ${ }^{2}$, 曹 静 $^{1}$, 王永锋 ${ }^{1}$, 王亚楠 ${ }^{1}$
}

(1. 西安航空学院 材料工程学院, 西安 710077; 2. 商洛学院 陕西省尾矿资源综合利用重点实验室, 商洛 726000)

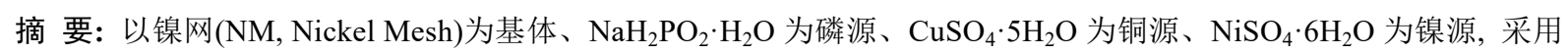
一步水热法合成镍铜磷复合电催化剂, 对制备工艺进行优化, 并通过不同方法进行形貌、结构、组成和电催化性能 表征。结果表明: 当溶液中镍、铜、磷的配比为 $8: 1: 20$ 时, 在 $140{ }^{\circ} \mathrm{C}$ 水热合成 $24 \mathrm{~h}$, 制得主晶相为 $\mathrm{Ni}_{2} \mathrm{P}$ 和 $\mathrm{Cu}_{3} \mathrm{P}$ 、 具有三级微纳结构的镍铜磷复合电催化剂。在电流密度为 $10 \mathrm{~mA} \cdot \mathrm{cm}^{-2}$ 时, $\mathrm{NiCuP} / \mathrm{NM}$ 的催化析氢及肼氧化过电势分 别为 165 和 $49 \mathrm{mV}$; 在双电极体系中, 同电流密度下的分解槽压仅为 $0.750 \mathrm{~V}$, 催化 $24 \mathrm{~h}$ 后分解槽压几乎保持不变, 展现出优异的催化稳定性。无论三电极体系还是双电极体系均表现出优异的催化活性。分析认为, 电催化活性面积 为空白镍网的近 14 倍, 为电催化过程提供了大量的活性位点; 掺入 $\mathrm{P}$ 改变了 $\mathrm{Ni} 、 \mathrm{Cu}$ 原子的电子结构, 提高了材料 的本征肼氧化活性, 两者的协同作用促进了电催化活性的提升。本研究为纳米尺度的合成提供了一个新的视角, 有 望推动新型纳米孔结构材料在燃料电池和传感器应用中的发展。

关 键 词: 镍铜复合磷化物; 混合水电解; 析氢反应; 肼氧化反应

中图分类号: O611 文献标识码: A

\section{Hydrothermal Synthesized Nickel Copper Composite Phosphides as Bifunctional Electrocatalysts for Hydrogen Evolution and Hydrazine Oxidation}

\author{
LI Zhao ${ }^{1}$, SUN Qiangqiang ${ }^{2}$, CHEN Suoqian ${ }^{2}$, ZHOU Chunsheng ${ }^{2}$, \\ CAO Jing ${ }^{1}$, WANG Yongfeng ${ }^{1}$, WANG Yanan ${ }^{1}$
}

(1. School of Materials Engineering, Xi' an Aeronautical University, Xi' an 710077, China; 2. Shaanxi Key Laboratory of Comprehensive Utilization of Tailings Resources, Shangluo University, Shangluo 726000, China)

\begin{abstract}
Herein, we report a kind of $\mathrm{NiCu}$-based composite phosphides electrocatalyst(NiCuP/NM), which was prepared in situ on nickel mesh substrate by one-step hydrothermal method with $\mathrm{NaH}_{2} \mathrm{PO}_{2}, \mathrm{CuSO}_{4}, \mathrm{NiSO}_{4}$ as initial materials. The morphology, crystal structure, composition, and electrocatalytic performance of NiCuP/NM were characterized. Under the optimal preparation conditions of $\mathrm{Ni}, \mathrm{Cu}$ and $\mathrm{P}($ molar ratio $8: 1: 20)$, hydrothermal synthesis at $140{ }^{\circ} \mathrm{C}$ for $24 \mathrm{~h}$, the obtained composite electrocatalyst displayed three-level micro-nanostructure with $\mathrm{Ni}_{2} \mathrm{P}$ and $\mathrm{Cu}_{3} \mathrm{P}$ as main crystal phases. At the current density of $10 \mathrm{~mA} \cdot \mathrm{cm}^{-2}$, the required HER (Hydrogen Evolution Reaction) overpotential and HzOR (Hydrazine Oxidation Reaction) potential of NiCuP/NM were 165 and $49 \mathrm{mV}$, respectively. In the two-electrode system, the decomposition tank pressure for the $\mathrm{NiCuP} / \mathrm{NM}$ cell at the same current density was only $0.750 \mathrm{~V}$ which remained substantially unchanged for $24 \mathrm{~h}$ catalysis, exhibiting excellent catalytic stability. NiCuP/NM displays prominent electrocatalytic performances towards HER or HzOR in both three-electrode and two-electrode systems, which can be ascribed to two aspects. On the one hand, the 14-fold elec-
\end{abstract}

收稿日期：2019-12-18; 收到修改稿日期：2020-03-18

基金项目：西安市科技计划项目(GXYD9.2); 陕西省自然科学基金(2019JM-092)

Xi'an Science and Technology Project (GXYD9.2); Shaanxi Natural Science Foundation (2019JM-092)

作者简介: 李 兆(1986-), 男, 副教授. E-mail: pylizhao@163.com

LI Zhao(1986-), male, associate professor. E-mail: pylizhao@163.com 
trochemical active surface area compared with original nickel mesh enables $\mathrm{NiCuP} / \mathrm{NM}$ expose huge number of catalytic active sites in both HER and HzOR. On the other hand, the electronic structure modification of $\mathrm{Ni}$ and $\mathrm{Cu}$ atoms induced by doping $\mathrm{P}$ atom brings great improvement of intrinsic HzOR activity of electrode materials. This study provides a new perspective for nanoscale synthesis and promotes the development of novel nanopores in fuel cell and energy conversion applications.

Key words: nickel copper-based phosphides; hybrid water electrolysis; hydrogen evolution reaction; hydrazine oxidation

氢能作为一种高热值、零污染且可再生的二次 能源载体, 被人们寄予厚望。要实现氢能的工业化 应用，其上游制氢技术是关键。相比化石燃料重整 制氢和微生物制氢, 电解水制氢 ${ }^{[1-3]}$ 具有原料来源 广、碳排放低、环境友好且可循环利用的优点, 被 认为是通向氢经济的必由之路。水电解过程中在碱 性电解槽的阳极发生水氧化反应(Oxygen Evolution Reaction, OER), 因为氧原子间成键具有较高的活 化能垒, 使得动力学缓慢的 OER 反应严重制约了 水电解的能源转换效率 ${ }^{[4-5]}$ 。因此, 寻找新氧化物种 的氧化反应替代 OER 反应, 成为降低水电解过程的 电能消耗、提高能源转换效率的重要途径, 常用的 替代氧化物种有甲醇、乙醇、乙二醇、氨以及尿素 等 ${ }^{[6-9]}$ 。近年来, 水合肼 $\left(\mathrm{N}_{2} \mathrm{H}_{4} \cdot \mathrm{H}_{2} \mathrm{O}\right)$ 作为高能量密度 的氢载体被广泛应用于直接肼燃料电池(Direct Hydrazine Fuel Cell, DHFCs) ${ }^{[10-11]}$, 在 DHFCs 的阳极发 生水合肼的氧化反应(HzOR), 改善 $\mathrm{HzOR}$ 的电氧化 活性, 可以直接提高 DHFCs 的能源转换效率。受此 启发, 利用 HzOR 替代 OER, 则能有效降低水电解 过程的分解槽压, 进而降低此过程的电能消耗, 促 进水分解, 高效产氢。

常用于析氢或肼氧化的电催化剂主要有金属合 金、金属磷化物、硫化物及嗍化物等 ${ }^{[12-13]}$ 。Pt 基贵 金属是目前最高效、商业应用最广泛的析氢或肼氧 化电催化剂, 然而其稀缺性及高成本极大限制了在 制氢技术中的规模化应用。为推进电解水制氢的工 业化进程, 设计开发低成本、高活性、环境友好的 电催化剂是电解水制氢产业发展的关键。根据 Brewer-Engel 价键理论 ${ }^{[14]}$, 铜的 d 电子与镍的半空 $\mathrm{d}$ 轨道结合形成金属间的协同电催化作用, 有助于提 高析氢反应的本征催化活性; 加上低廉的成本及丰 富的储量, 使得多元镍铜合金电极 ${ }^{[15-16]}$ 成为替代商 业 $\mathrm{Pt} / \mathrm{C}$ 应用于工业化制氢最有前景的电极材料。目 前, 镍铜基电极材料的制备以及在电催化析氢中的 应用已经取得一定进展, 然而局限于暴露出的催化 活性位点不足及有限的本征活性, 距离其在水分解
制氢领域的工业化应用仍相去甚远。

水热合成技术具有产物纯度高、颗粒均匀、晶 型完整、形貌易控等优点, 被广泛应用于电催化材 料的设计开发 ${ }^{[17-18]}$ 。在电催化水分解的应用中, 过 渡金属磷化物不仅可以作为析氢反应的质子受体, 还可以通过减小氢分子的成键强度促进氢气从催化 剂表面的逸出。因此, 磷化处理 ${ }^{[19]}$ 常作为向过渡金 属析氢催化剂引入杂原子 $\mathrm{P}$ 的有效途径, 改善其在 酸性或碱性介质中的电催化活性及稳定性。郑一雄 课题组 ${ }^{[20]}$ 通过化学镀法与恒电位刻蚀技术联用在 低碳钢基板上获得了纳米多孔结构的非晶态 $\mathrm{NiCuP}$ 电催化剂, 测定其在肼氧化过程的扩散系数及速率 常数, 发现其氧化还原能力相对稳定, 具有一定的 肼氧化活性。赵川课题组 ${ }^{[21]}$ 利用氢气泡模板法与中 温磷化技术相结合在镍网基底获得了微米级多孔结 构的晶态 $\mathrm{NiCuP}$ 电催化剂, 其在全 $\mathrm{pH}$ 范围内表现 出优异的析氢性能。局限于复杂的制备过程及单一 的电催化活性, 在析氢及肼氧化应用中, 镍铜磷双 功能催化剂尚未见报道。鉴于此, 为了获得低成本、 高效、满足析氢与肼氧化双功能应用的电催化剂, 本研究以镍网( NM)为基板, 采用一步水热合成法制 备具有纳米结构的镍铜磷复合电催化剂。同时, 优 化催化剂的制备工艺参数, 评价其在析氢、訮氧化 以及双功能电解池中的电化学性能。

\section{1 实验方法}

\section{1 试剂}

六水硫酸镍、五水硫酸铜、一水合次亚磷酸钠、 氢氧化钾、硫酸、盐酸、硝酸和无水乙醇均为分析 纯, 购自国药集团试剂有限公司; 超纯水采用 Millipore 超纯水系统制备。

\section{2 复合电极的制备}

(1)镍网的预处理

将纯度为 $99.9 \%$ 、孔径为 $0.1 \mathrm{~mm}$ 的镍网(150 目, 安平县鸿运金属制品有限公司)裁剪为 $2.0 \mathrm{~cm} \times 0.5 \mathrm{~cm}$ 
的镍网条, 分别在 $5 \mathrm{~mol} \cdot \mathrm{L}^{-1}$ 盐酸和 $95 \%$ 乙醇溶液中 超声浸泡 $15 \mathrm{~min}$, 除去表面的氧化物及表层油污, 以 去离子水清洗三次后储于乙醇溶液中, 每次使用前 真空干燥。

(2) NiCuP/NM 电极的制备

以镍网为基板, 在硫酸镍、硫酸铜及次亚磷酸 钠的混合液中, 采用一步水热法于高压反应釜中合 成 $\mathrm{NiCuP} / \mathrm{NM}$ 复合电极。以 $\mathrm{NiSO}_{4} 、 \mathrm{CuSO}_{4}$ 及 $\mathrm{NaH}_{2} \mathrm{PO}_{2}$ 为反应底物, 控制 $\mathrm{CuSO}_{4}$ 浓度为 $1 \mathrm{mmol} \cdot \mathrm{L}^{-1}$, 加入不 同浓度的 $\mathrm{NiSO}_{4}$ 调节镀液中的镍铜比, 再加入一定 浓度的 $\mathrm{NaH}_{2} \mathrm{PO}_{2}$ 溶液, 移至 $25 \mathrm{~mL}$ 聚四氟乙烯的内 胆中(填充度 $80 \%$ ), 加盖并超声分散 $15 \mathrm{~min}$, 移入 高压反应釜中。将釜体放入预先升温至设定温度的 恒温干燥箱中保温一定时间。反应完毕后, 冷却至 室温, 分别以超纯水和乙醇洗涤 3 次, 在空气中自 然晾干后, 即可进行后续物理表征测试, 并作为水 分解电解池的阴极或阳极进行电化学性能测试。

\section{3 物理表征}

将制备的电极材料, 经去离子水冲洗、乙醇溶 液浸泡、空气自然干燥后, 以日立高新技术公司生 产的冷场发射扫描电镜(SU-8020, FESEM, 二次电 子成像, 加速电压 $10 \mathrm{kV}$ )观测其形貌结构, 以电镜自 带的能谱仪(EDX)进行元素组成及分布测试(测试电 压 $20 \mathrm{kV})$ 。采用德国布鲁克公司的高分辨 $\mathrm{X}$ 射线衍 射仪(D8 Advance, XRD)测定电极样品的晶型结构。 测试的条件为: 电压 $40 \mathrm{kV}$, 管电流 $40 \mathrm{~mA}, \mathrm{Cu} \mathrm{K \alpha}$ 辐射源, $\lambda=0.15418 \mathrm{~nm}, 2 \theta=30^{\circ} \sim 80^{\circ}$, 扫速为 $8\left(^{\circ}\right) / \mathrm{min}$ 。 将镍铜合金薄膜直接从新制的 $\mathrm{NiCu} / \mathrm{NM}$ 电极上超 声 $30 \mathrm{~min}$ 后剥离, 在 $2 \mathrm{~mL}$ 离心管中, 用乙醇作为分 散介质超声分散 $30 \mathrm{~min}$ 。将分散液涂覆在透射专用 碳膜上, 待乙醇挥发后, 以冷场发射透射电子显微 镜(Tecnai G2 F20, TEM, 工作电压 $200 \mathrm{kV}$ )进行常规 形貌及高分辨测试。

\section{4 电化学测试}

采用标准的三电极体系, 在 CHI760E 电化学工 作站上进行镍铜磷复合电极的电化学性能测试, 电 极组成: 制备电极为工作电极(有效电极面积 $1.4 \mathrm{~cm} \times$ $0.5 \mathrm{~cm}$, 后续电化学测试均以此计), 饱和甘录电极 (饱和 $\mathrm{KCl}, \mathrm{SCE}$ ) 为参比电极, 石墨棒为对电极, 电解 质溶液为 $1 \mathrm{~mol} \cdot \mathrm{L}^{-1} \mathrm{KOH}\left(\right.$ 含 $0.5 \mathrm{~mol} \cdot \mathrm{L}^{-1} \mathrm{~N}_{2} \mathrm{H}_{4} \cdot \mathrm{H}_{2} \mathrm{O}$ )。

采用线性扫描伏安法(LSV)测定电催化剂的析 氢及肼氧化性能, 析氢扫描电位窗口为 $-0.8 \sim-1.5 \mathrm{~V}$, 扫速为 $2 \mathrm{mV} / \mathrm{s}$, 极化曲线均经过 $95 \%$ 电阻补偿; 肼 氧化扫描电位窗口为 $-1.1 \sim 0.4 \mathrm{~V}$, 扫速为 $5 \mathrm{mV} / \mathrm{s}$, 极 化曲线不进行电阻补偿。所有测得电位值按 $E_{\mathrm{RHE}}=$ $E_{\mathrm{SCE}}+0.242 \mathrm{~V}+0.059 \mathrm{pH}$ 相对于标准氢电极电势
(RHE)进行校正, $0.242 \mathrm{~V}$ 为室温下饱和甘录电极的 标准电极电势。

采用线性扫描伏安法(LSV)测定双功能电解池 的槽电压 - 电流曲线, 测试参数为: 扫描电位窗口 $0 \sim 1.0 \mathrm{~V}$ (全水分解 $1.2 \sim 2.7 \mathrm{~V}$ ), 扫描速度 $5 \mathrm{mV} \cdot \mathrm{s}^{-1}$ 。 采用计时电位法测试双功能电解池在水合肼电解过 程中槽电压随时间的变化情况。测试参数: 计时电 位法, $100 \mathrm{~mA} \cdot \mathrm{cm}^{-2} / 24 \mathrm{~h}$ 。在非法拉第感应窗口 $-0.05 \sim 0.05 \mathrm{~V}$ 下, 测定 $\mathrm{NiCuP} / \mathrm{NM}$ 电极在不同扫速 (5、10、25、50、100、200 mV $\left.\cdot \mathrm{s}^{-1}\right)$ 下的循环伏安 $(\mathrm{CV})$ 曲线和充电双电层库伦曲线, 依据充电电流 $\left(i_{\mathrm{c}}\right)$ 与扫 描速率 $(v)$ 的线性关系, 获得制备电极的双电层电容 $\left(C_{\mathrm{dl}}\right)$ 。按式 $\mathrm{ECSA}=C_{\mathrm{dl}} / C_{\mathrm{s}}$ 计算求得 ECSA (Electrochemical active surface area), 式中: $C_{\mathrm{s}}$ 为单位电化学 活性面积的镍基材料在 $1.0 \mathrm{~mol} \cdot \mathrm{L}^{-1} \mathrm{KOH}$ 溶液中的 比活性，通常取 $0.04 \mathrm{mF} \cdot \mathrm{cm}^{-2} \cdot \mathrm{cm}^{-2} \mathrm{ECSA}^{[22]}$ 。

\section{2 结果与讨论}

\section{$2.1 \mathrm{NiCuP} / \mathrm{NM}$ 电催化剂的物理表征}

以 $\mathrm{NiCuP} / \mathrm{NM}$ 的表观形貌为研究指标, 对一步 水热法的制备方案及参数进行优化(详见补充材料 S1 S4), 优选的方案及制备方案为: 原始物料组成为 $8 \mathrm{mmol} \cdot \mathrm{L}^{-1} \mathrm{NiSO}_{4}, 1 \mathrm{mmol} \cdot \mathrm{L}^{-1} \mathrm{CuSO}_{4}, 20 \mathrm{mmol} \cdot \mathrm{L}^{-1}$ $\mathrm{NaH}_{2} \mathrm{PO}_{2}$, 溶液总体积 $20 \mathrm{~mL}$ (填充度 $80 \%$ ); 一步水 热合成法, 在 $140{ }^{\circ} \mathrm{C}$ 保温 $24 \mathrm{~h}$ 。

利用 FESEM、EDX、TEM 及 XRD 对优选复合 电催化剂的表观形貌、组成、元素分布及物相进行 测定, 结果如图 1 和图 2 所示。

图 1(a c) 为优选的复合电催化剂 $\mathrm{NiCuP} / \mathrm{NM}$ 在 不同倍数下的微观形貌。由图 1(a)可以看到复合电 催化剂很好地继承了镍网的矩形(边长约 $150 \mu \mathrm{m}$ )多 孔网络结构, 为催化过程中气体产物的消散提供了 最为便捷的通道。从图 1(b,c)可以发现，镍网表面的 镍铜磷电催化剂由平均粒径为 $500 \mathrm{~nm}$ 球状结构以 及纳米片交织互联形成的表层线毛结构构成，一级 微孔以及二级纳米结构构成了 $\mathrm{NiCuP} / \mathrm{NM}$ 的三级复 合结构, 在催化应用中不仅有利于催化剂与 $\mathrm{Ni}$ 基底 之间的电子传输, 更有利于电解液向固相电极内部 的渗透，保证了反应物种与催化剂表面活性位的充 分接触, 使其最大限度地发挥电催化活性。通过 $\mathrm{NiCuP} / \mathrm{NM}$ 的组成分析(图 1(d))发现, 镍网表面的复 合薄膜由 $\mathrm{Ni} 、 \mathrm{Cu} 、 \mathrm{P} 、 \mathrm{O}$ 四种元素组成, $\mathrm{O}$ 元素来源 于部分中间产物亚磷酸盐。图 1(e)为 $\mathrm{NiCuP} / \mathrm{NM}$ 的 元素分布图, 其中 $\mathrm{Ni} 、 \mathrm{Cu} 、 \mathrm{P} 、 \mathrm{O}$ 四元素均匀地分 布在镍铜磷化物的复合薄膜中。 


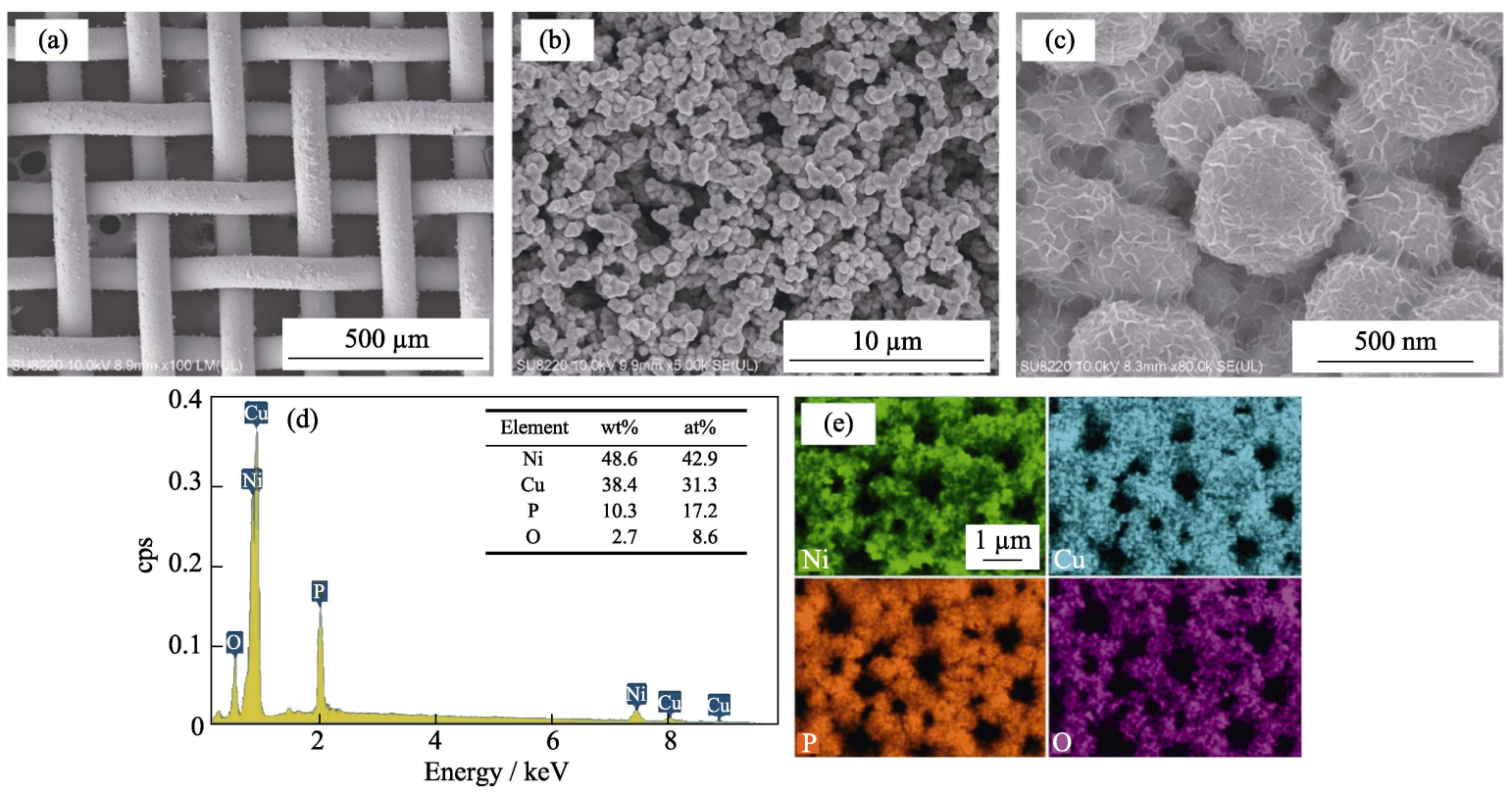

图 $1 \mathrm{NiCuP} / \mathrm{NM}$ 复合电极的(a c)FESEM 照片、(d)EDX 谱图及(e)元素分布图

Fig. 1 (a-c) FESEM images, (d) EDX spectra and (e) element mappings of NiCuP/NM electrode
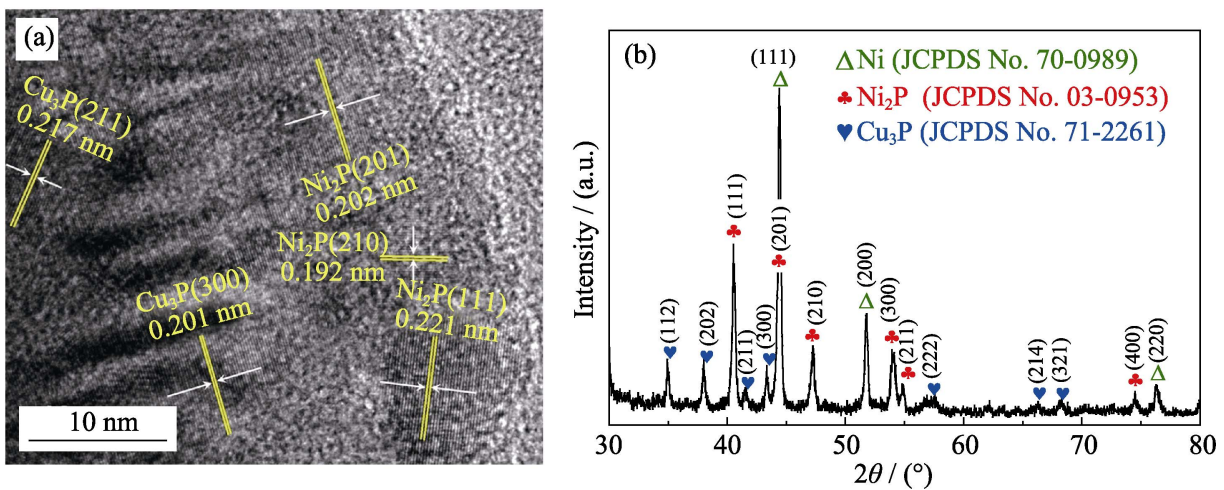

图 $2 \mathrm{NiCuP} / \mathrm{NM}$ 电催化剂的(a)HRTEM 照片及(b)XRD 图谱

Fig. 2 (a) HRTEM image and (b) XRD pattern of NiCuP/NM electrocatalyst

采用 HRTEM 和 XRD 探究 NiCuP/NM 复合薄 膜的晶型结构, 结果见图 2。在 HRTEM 照片(图 2(a)) 中, 可以观察到大量密集排列、清晰的晶格条纹, 晶 面间距为 0.217 和 $0.201 \mathrm{~nm}$ 的晶格条纹分别归属于 $\mathrm{Cu}_{3} \mathrm{P}$ 的(211)和(300)晶面，而晶面间距为 0.221 、 0.202 和 $0.192 \mathrm{~nm}$ 的晶格条纹分别归属于 $\mathrm{Ni}_{2} \mathrm{P}$ 的

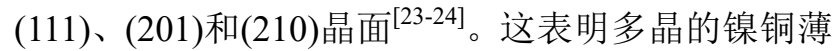
膜中形成了 $\mathrm{Cu}_{3} \mathrm{P}$ 和 $\mathrm{Ni}_{2} \mathrm{P}$ 物相, 进一步验证了一步 水热法引入杂原子 $\mathrm{P}$ 的可行性。

图 2(b)为镍铜磷复合薄膜的 XRD 图谱, 图中有 3 个特征衍射峰, 对应于 Ni(JCPDS 70-0989) (111)、 (200)和(220)晶面, 表明存在晶态金属镍, 这是 $X$ 射 线穿透薄膜打在镍网金属骨架上所致。图中 $\mathrm{Ni}_{2} \mathrm{P}(\mathrm{JCPDS}$ 03-0953)的(111)、(201)、(210)、(300)、 (211)、(400) 晶面衍射峰以及 $\mathrm{Cu}_{3} \mathrm{P}$ (JCPDS 71-2261) 的(112)、(202)、(211)、(300)、(222)、(214)、(321)
晶面衍射峰，表明镍铜磷复合薄膜中 $\mathrm{Ni} 、 \mathrm{Cu} 、 \mathrm{P}$ 主 要以晶态 $\mathrm{Ni}_{2} \mathrm{P}$ 和 $\mathrm{Cu}_{3} \mathrm{P}$ 物相存在, 这与 TEM 分析 结果相一致。峰形细而尖锐表明所得材料具有较高 的结晶度。

\section{$2.2 \mathrm{NiCuP} / \mathrm{NM}$ 电催化剂的电化学性能测试}

为表征所制备电催化剂的电化学性能, 采用 LSV 测定 $\mathrm{NiCuP} / \mathrm{NM}$ 在 $1 \mathrm{~mol} \cdot \mathrm{L}^{-1} \mathrm{KOH}\left(\right.$ 含 $0.5 \mathrm{~mol} \cdot \mathrm{L}^{-1}$ $\mathrm{N}_{2} \mathrm{H}_{4} \cdot \mathrm{H}_{2} \mathrm{O}$ ) 溶液中的析氢、肼氧化极化曲线, 如图 3 所示。

由图 3(a,c) 可知, 在电流密度为 $10 \mathrm{~mA} \cdot \mathrm{cm}^{-2}$ 时, $\mathrm{NiCuP} / \mathrm{NM}$ 的析氢过电位及肼氧化电位仅为 165 和 $49 \mathrm{mV}$ ，远小于同条件下基板 $\mathrm{NM}$ 的 201 和 $180 \mathrm{mV}$, 表明镍网负载镍铜磷后, 在 HER(Hydrogen Evolution Reaction)和 $\mathrm{HzOR}$ 中的催化活性得到显著提升, 这除了取决于镍铜金属间的协同效应，还与杂原子 $\mathrm{P}$ 的引入对本征活性的提升有关。 

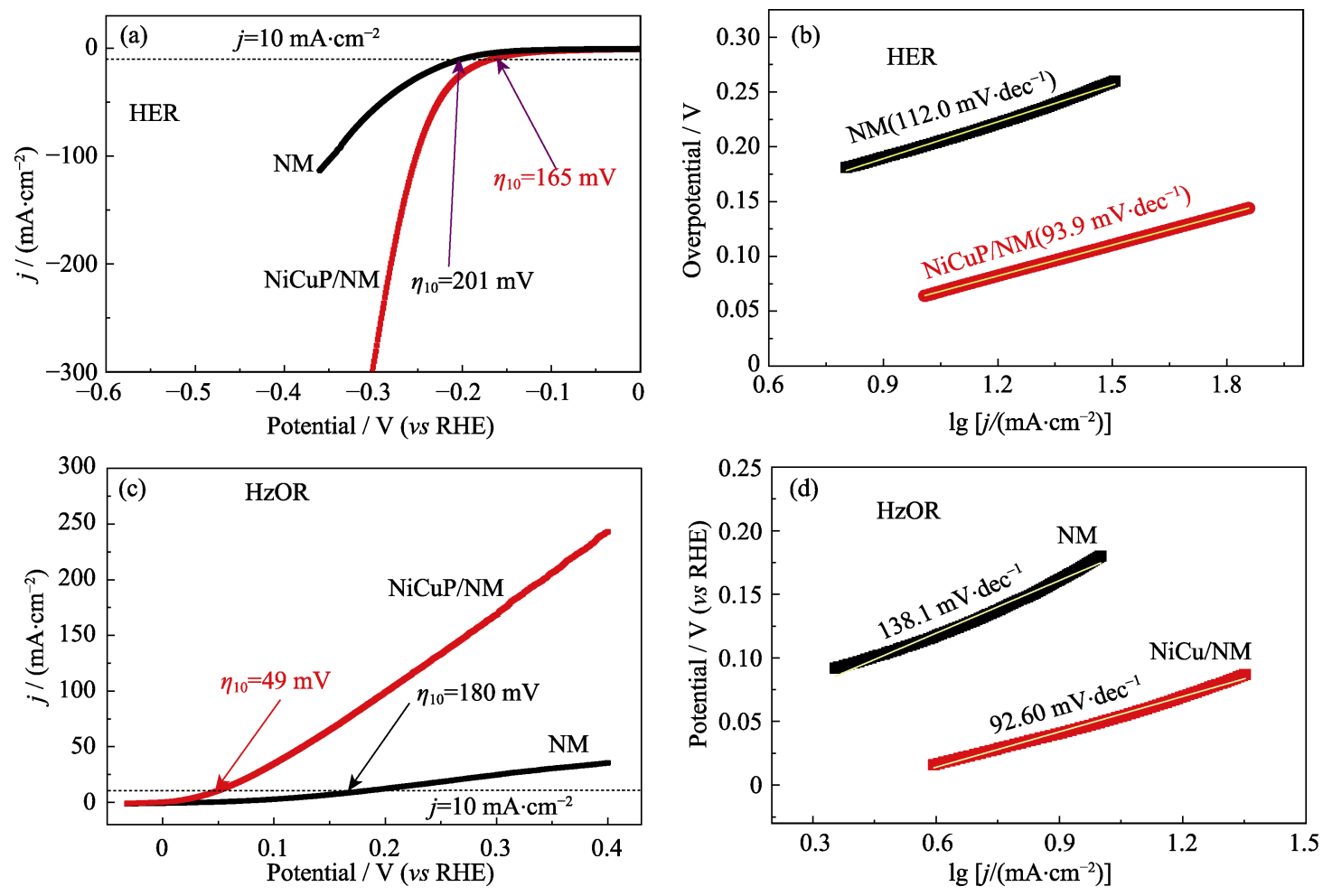

图 $3 \mathrm{NiCuP} / \mathrm{NM}$ 复合电极在 $\operatorname{HER}(\mathrm{a}, \mathrm{b})$ 及 $\operatorname{HzOR}(\mathrm{c}, \mathrm{d})$ 中的 $(\mathrm{a}, \mathrm{c}) \mathrm{LSV}$ 极化曲线及(b, d)Tafel 曲线

Fig. 3 (a, c) LSV polarization curves and (b, d) Tafel curves of NiCuP/NM composite electrode towards HER (a, b) and HzOR (c, d)

为了评价 $\mathrm{NiCuP} / \mathrm{NM}$ 在电催化反应中的动力学 特性, 分别测定了其在 HER 和 HzOR 过程中的塔菲 尔(Tafel)斜率。由图 3(b,d)可知, 在电催化析氢和肼 氧化过程中, $\mathrm{NiCuP} / \mathrm{NM}$ 电极的 Tafel 斜率分别为 93.9 和 $92.6 \mathrm{mV} \cdot \mathrm{dec}^{-1}$, 同样显著低于同条件下基板 $\mathrm{NM}$ 的 112.0 和 $138.1 \mathrm{mV} \cdot \mathrm{dec}^{-1}$, 表明 $\mathrm{NiCuP} / \mathrm{NM}$ 在 $\mathrm{HER}$ 和 $\mathrm{HzOR}$ 中具有良好的动力学特性, 这与催化 过程中电极表面的电子传递能力有关。同时, 塔菲 尔(Tafel)斜率是评价析氢反应动力学及反应机理的 重要参数, 用以判定电极表面析氢反应的决速步 骤。 $\mathrm{NiCuP} / \mathrm{NM}$ 电极在析氢过程的 Tafel 斜率为 $93.9 \mathrm{mV} \cdot \mathrm{dec}^{-1}$, 表明 Volmer 反应为 $\mathrm{NiCuP} / \mathrm{NM}$ 电极 表面析氢过程的决速步骤, 即反应速率是由金属表 面吸附氢原子的电化学吸附过程所决定的 ${ }^{[25-26]}$ 。

基于 $\mathrm{NiCuP} / \mathrm{NM}$ 在 $\mathrm{HER}$ 和 $\mathrm{HzOR}$ 中展现出的 优良的催化活性, 将其同时作为电解池的阴极和阳 极, 构建电解水合肼溶液的双功能电解池, 测定了 双电极体系在混合水电解过程的催化性能, 结果如 图 4 所示。

图 4(a)描述了电流密度随双功能电解池分解槽 压的响应曲线。图中 $\mathrm{NiCuP} / \mathrm{NM}|| \mathrm{NiCuP} / \mathrm{NM}$ 电解池 (HER\&HzOR) 在电流密度为 100 和 $200 \mathrm{~mA} \cdot \mathrm{cm}^{-2}$ 时 的槽电压分别为 0.750 和 $1.024 \mathrm{~V}$, 优于目前多数非贵 金属双功能电催化剂。作为对比, 测定了 $\mathrm{NiCuP} / \mathrm{NM}$ 电
极对在 $1 \mathrm{~mol} \cdot \mathrm{L}^{-1} \mathrm{KOH}$ 溶液中的全水分解过程的极 化曲线(HER\&OER)。结果发现, 在 $100 \mathrm{~mA} \cdot \mathrm{cm}^{-2}$ 的 电流密度下, 其水合肼混合电解过程的电解槽压为 $0.750 \mathrm{~V}$, 远低于全水分解过程 $(1.921 \mathrm{~V})$, 表明以 $\mathrm{HzOR}$ 反应替换阳极的 OER 反应, 不但可以大幅降 低水电解过程的电能消耗, 而且可以显著提高电池 的产氢效率。电极材料的稳定性是评价电催化剂工 业应用价值的重要依据, 我们采用计时电位法测定 了 $\mathrm{NiCuP} / \mathrm{NM}$ 构成的双电极电解池在 $100 \mathrm{~mA} \cdot \mathrm{cm}^{-2}$ 的时间-电位响应曲线(图 4(b))。由图可知, 水合肼 混合液在长时间电解过程中的分解槽压基本保持不 变。在连续 $24 \mathrm{~h}$ 的恒电流稳定性测试中, 相应的槽 压波动不超过 $20 \mathrm{mV}$, 表明 $\mathrm{NiCuP} / \mathrm{NM}$ 在长时间混 合催化过程中具有优异的稳定性。从电解 $24 \mathrm{~h}$ 后的 SEM 照片 (图 4(c)) 中可以看出其线毛球的微纳结 构保持完好, 进一步表明其具有高的机械强度及优 异的耐用性, 为其在电解水制氢领域的工业应用奠 定了基础。

图 4(d)为气体产物 $\mathrm{H}_{2} 、 \mathrm{~N}_{2}$ 的气相色谱图。结果 发现, $\mathrm{H}_{2} 、 \mathrm{~N}_{2}$ 气体产物的体积比为 2.7 , 近似于化学 计量比 3 。为进一步定量分析电解过程产生的氢气, 利用经校准的压力传感器实时测定 $\mathrm{H}$ 型电解池阴极 区的压力变化, 进而对混合电解过程产生的氢气进 行定量分析。图 4(e)中的点和线分别为实测与理论 

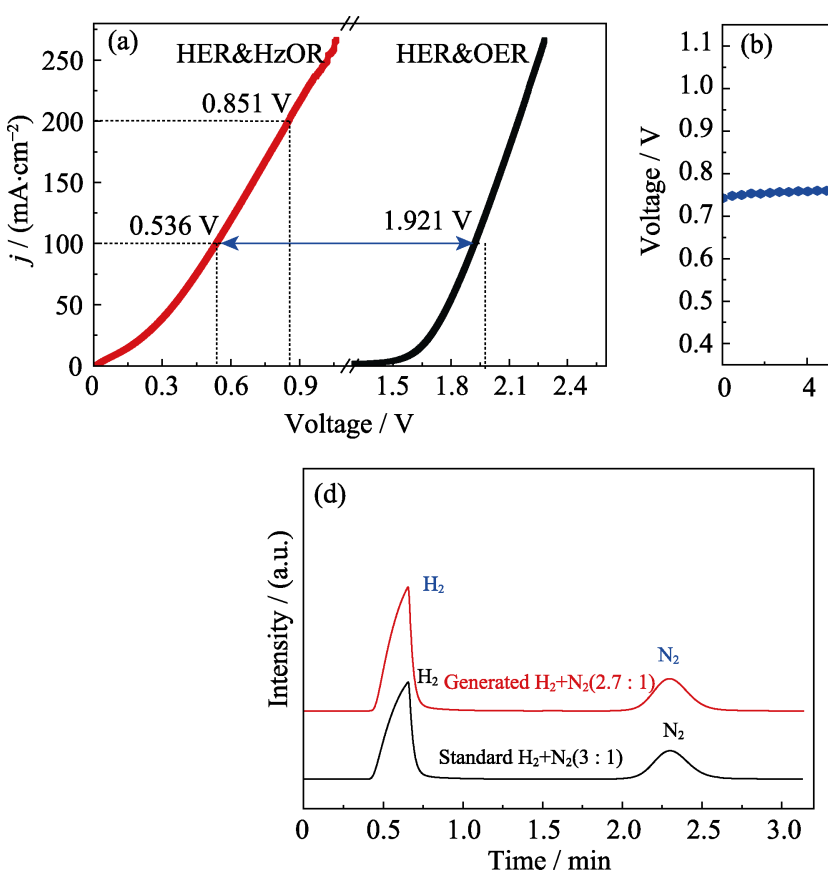
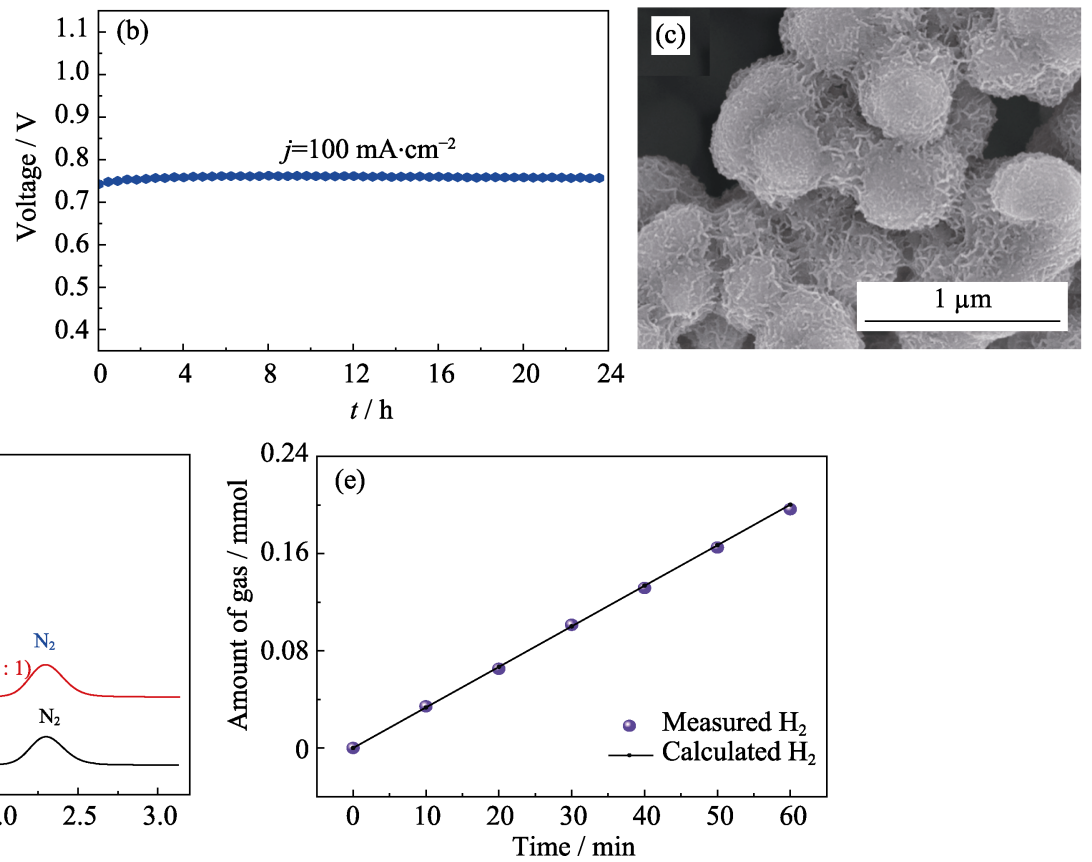

图 $4 \mathrm{NiCuP} / \mathrm{NM}$ 电极在双电极体系中的(a)LSV 极化曲线, (b)稳定性测试曲线, (c)双功能电解 $24 \mathrm{~h}$ 后的 SEM 照片, (d)气体产物的气相色谱图, (e)理论与实际产氢量的对比图

Fig. 4 (a) LSV polarization curves, (b) stability test by chronopotentiometry, (c) SEM image after 24 h hybrid electrolysis, (d) gas chromatography (GC) spectra of gas products for NiCuP/NM in the two-electrode system, and (e) the amount comparison of calculated $\mathrm{H}_{2}$ and measured $\mathrm{H}_{2}$

产氢量。在不同的采样点(电解时间), 由 $\mathrm{NiCuP} / \mathrm{NM}$ 组成的双功能电解槽的产氢量与理论值几乎重合, 说明镍铜电极材料在电解过程中的电解效率接近 $100 \%$ 。结合气体产物 $\mathrm{H}_{2}$ 和 $\mathrm{N}_{2}$ 的体积比接近化学计 量比, 表明水合肼在电解过程中被完全分解, 且除 了 $\mathrm{H}_{2}$ 和 $\mathrm{N}_{2}$ 之外没有其他气体副产物。

\section{$2.3 \mathrm{NiCuP} / \mathrm{NM}$ 高性能原因探究}

无论是三电极体系还是双电极体系, $\mathrm{NiCuP} / \mathrm{NM}$ 在水合肼溶液电解过程均表现出优良的催化活性。 为研究 $\mathrm{NiCuP} / \mathrm{NM}$ 电催化剂在催化过程中高活性的 原因, 我们测定了 $\mathrm{NiCuP} / \mathrm{NM}$ 电极在析氢过程中的 循环伏安 (CV)曲线(图 5(a)), 根据图中电位为 0 时不 同扫速下的响应电流，绘制了相应的充电双电层库仑 曲线 (图 5(b)), 测得 $\mathrm{NiCuP} / \mathrm{NM}$ 的 $C_{\mathrm{dl}}$ 为 $3.54 \mathrm{mF} \cdot \mathrm{cm}^{-2}$, ECSA 为 $88.5 \mathrm{~cm}^{2}$, 为同条件下空白镍网 $\left(6.25 \mathrm{~cm}^{2}\right)^{[27]}$ 的 14 倍。分析认为, 矩形微孔、纳米尺度的微球及 线毛结构构成了 $\mathrm{NiCuP} / \mathrm{NM}$ 电催化剂的三级微纳结 构, 在 HER 及 $\mathrm{HzOR}$ 反应中暴露出大量的活性点, 大幅改善了电极材料的催化活性。

电化学交流阻抗(EIS) 谱是评价固相电极与液 相电解质界面特性的重要手段, 可以反映催化剂表 面的动力学规律 ${ }^{[28]}$ 。图 5(c)描述了 $\mathrm{NiCuP} / \mathrm{NM}$ 电极 析氢过程中的 Nyquist 曲线。图中 $\mathrm{NiCuP} / \mathrm{NM}$ 在测试 频率区域呈现规整的半圆弧, 这源于在固相电极与
电解液两相界面上水分子的电子发生还原过程的电 荷转移电阻 $R_{\mathrm{ct}}$, 表明该电极表面 HER 动力学过程受 电化学反应控制 ${ }^{[29]}$ 。 $\mathrm{NiCuP} / \mathrm{NM}$ 的 $R_{\mathrm{ct}}\left(37.14 \Omega \cdot \mathrm{cm}^{-2}\right)$ 比 $\mathrm{NM}\left(92.68 \Omega \cdot \mathrm{cm}^{-2}\right)$ 更低, 这是因为随着金属 $\mathrm{Ni} 、 \mathrm{Cu}$ 的复合, 电极材料的导电性增强, 电荷传输速率随 之加快。同时, 镍铜磷的复合增强了法拉第过程的 界面接触, 促进了电极表面电荷转移及传质过程, 这主要归因于 $\mathrm{NiCuP} / \mathrm{NM}$ 电极独特的三级分层微纳 结构提供的大量反应通道及活性接触点, 使得两相 界面上的电荷传输阻力较小, 析氢反应具有较快的 动力学速率, 促进了单位电极表面积内的催化能力 的提升。

除了 ECSA，单位催化面积的固有活性是决定 电极材料析氢性能的根本原因。以 ECSA 的增加倍 数(相对空白 NM) 对析氢极化曲线进行校正, 通过 $\mathrm{NiCuP} / \mathrm{NM}$ 析氢活性的归一化处理, 研究其单位催 化活性位点的固有活性, 校正后的极化曲线及相应 的过电位如图 5(d)所示。结果发现, 在电流密度为 $10 \mathrm{~mA} \cdot \mathrm{cm}^{-2}$ 时, 归一化处理后 $\mathrm{NiCu} / \mathrm{NM}$ 电极的析氢 过电位为 $186 \mathrm{mV}$, 相比同条件下的 $\mathrm{NM}(202 \mathrm{mV})$ 下 降了 $16 \mathrm{mV}$, 验证了掺入磷确实会增强电极的本征 析氢活性。对比综合析氢过电位 $165 \mathrm{mV}$, 发现 ECSA 对 $\mathrm{NiCuP} / \mathrm{NM}$ 电极析氢活性的贡献甚至强于引入铜 磷对本征活性的提升。同时, 镍铜复合磷化物的主 

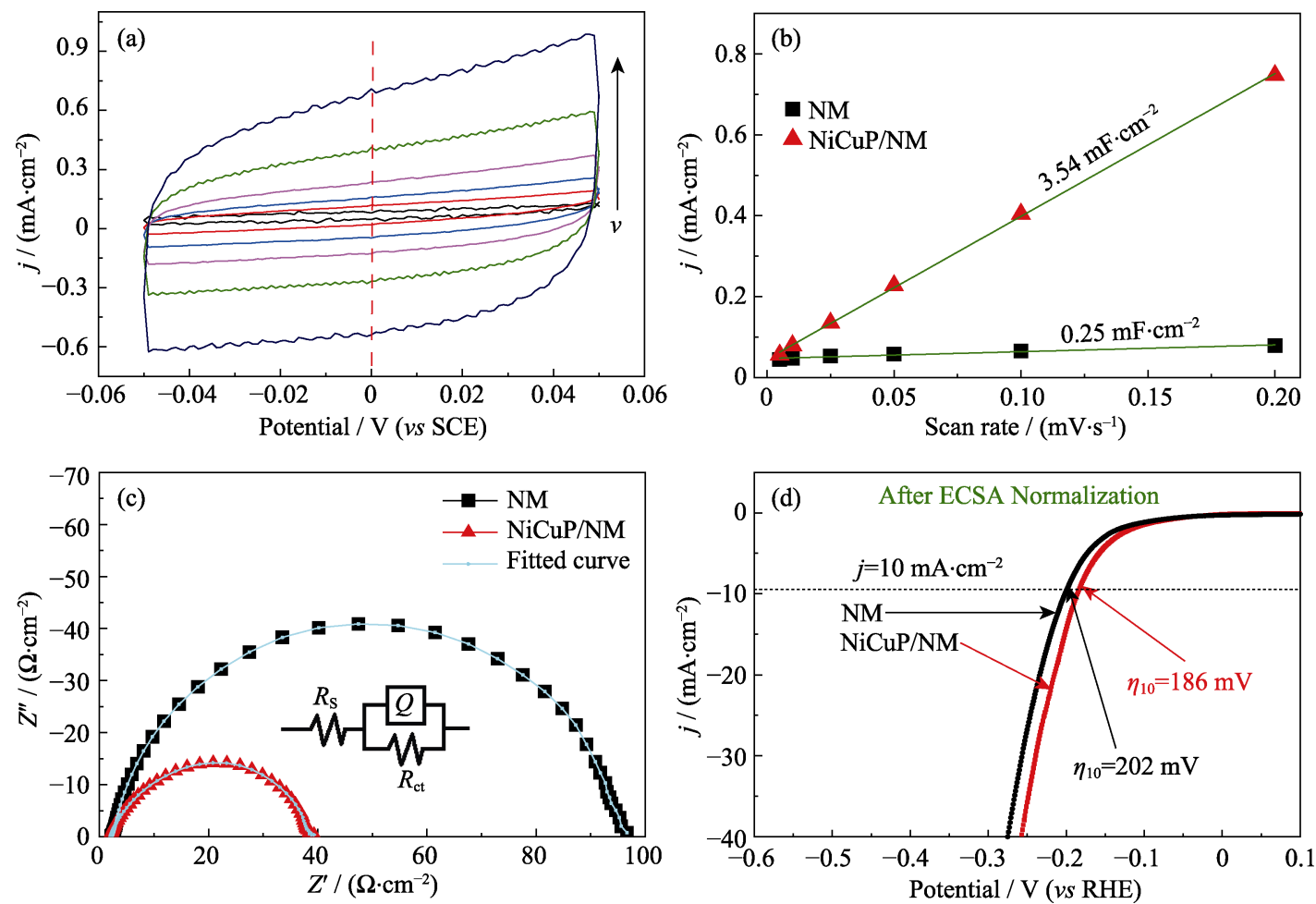

图 $5 \mathrm{NiCu} / \mathrm{NM}$ 电极在析氢过程中不同扫速 $\left(5 、 10 、 25 、 50 、 100 、 200 \mathrm{mV} \cdot \mathrm{s}^{-1}\right)$ 下的 $(\mathrm{a}) \mathrm{CV}$ 曲线及、

(b) 充电双电层库仑曲线、(c)Nyquist 曲线和(d)析氢活性的归一化曲线

Fig. 5 (a) CV curves at different scan rates $\left(5,10,25,50,100,200 \mathrm{mV} \cdot \mathrm{s}^{-1}\right)$, (b) Coulomb curves of charge double-layer capacitance, (c) Nyquist plots, and (d) LSV curves by ECSA normalization of NiCu/NM towards HER

晶相为 $\mathrm{Ni}_{2} \mathrm{P}$ 和 $\mathrm{Cu}_{3} \mathrm{P}$, 对肼氧化反应具有协同促进作 用, 使 $\mathrm{NiCuP} / \mathrm{NM}$ 在电解过程中表现出优良的肼氧 化性能。这是因为异质 $\mathrm{P}$ 原子成功引入到金属 $\mathrm{Ni}$ 和金属 $\mathrm{Cu}$ 的晶格中, 分别与两者形成化合键, $\mathrm{P}$ 原 子呈现电负性, 作为质子受体, 增加了 $\mathrm{Ni}^{\delta+}$ 和 $\mathrm{Cu}^{\delta+}$ 的正电荷 ${ }^{[30]}$, 促进了 $\mathrm{Ni} 、 \mathrm{Cu}$ 活性中心对 $\mathrm{N}_{2} \mathrm{H}_{4}$ 分子 的吸附。因此, 掺入的 $\mathrm{P}$ 通过修饰 $\mathrm{Ni} 、 \mathrm{Cu}$ 原子的电 子结构, 改善了电极材料的本征肼氧化活性。总之, 三级分层线毛球的结构特性, 与镍铜磷复合的协同 效应，共同促进了电极材料催化活性的显著提升。

\section{3 结论}

以镍网为基体, 采用一步水热法在优化的制备 参数条件下, 成功获得了具有多级微纳结构的 $\mathrm{NiCuP} /$ NM 电催化剂。采用 SEM、EDX、XRD 及电化学性 能测试进行表征。制得的镍铜磷复合催化剂由镍网 $150 \mu \mathrm{m}$ 的矩形微孔、其骨架上约 $500 \mathrm{~nm}$ 的球形颗 粒及颗粒表面包覆的纳米尺寸的线毛结构构成三级 结构。组成及物相分析发现, 复合薄膜由 $\mathrm{Ni} 、 \mathrm{Cu} 、 \mathrm{P}$ 、 $\mathrm{O}$ 四元素组成, 且 $\mathrm{Ni}_{2} \mathrm{P}$ 为 $\mathrm{Cu}_{3} \mathrm{P}$ 主晶相。 $\mathrm{NiCuP} / \mathrm{NM}$ 电极在 HER 和 $\mathrm{HzOR}$ 反应中表现出优良的催化活性, 在 $1.0 \mathrm{~mol} \cdot \mathrm{L}^{-1} \mathrm{KOH}+0.5 \mathrm{~mol} \cdot \mathrm{L}^{-1} \mathrm{~N}_{2} \mathrm{H}_{4} \cdot \mathrm{H}_{2} \mathrm{O}$ 的电解液
中, 在 $10 \mathrm{~mA} \cdot \mathrm{cm}^{-2}$ 电流密度下 $\mathrm{NiCuP} / \mathrm{NM}$ 需要的析 氢及肼氧化过电位分别为 165 和 $49 \mathrm{mV}$ 。在双电极 体系中, 同电流密度下的分解槽压仅为 $0.750 \mathrm{~V}$, 远 低于全水分解 $(1.921 \mathrm{~V})$, 同时还有优异的催化稳定 性。原因在于材料中的三级微纳结构为电催化反应 提供了大量的活性位点; 掺入 $\mathrm{P}$ 改变了 $\mathrm{Ni} 、 \mathrm{Cu}$ 原子 的电子结构, 提高了材料的本征肼氧化活性, 两者 协同促进了析氢及肼氧化催化活性的提升。无论三 电极体系还是双电极体系, $\mathrm{NiCuP} / \mathrm{NM}$ 均表现出优 异的催化活性, 使其在电催化析氢、肼燃料电池领 域展现出广阔的应用前景。

\section{补充材料}

本文相关补充材料可登陆 https://doi.org/10.15541/ jim20190640 查看。

\section{参考文献:}

[1] LAMY C, JAUBERT T, BARANTON S, et al. Clean hydrogen generation through the electrocatalytic oxidation of ethanol in a proton exchange membrane electrolysis cell (PEMEC): effect of the nature and structure of the catalytic anode. J. Power Sources, 2014, 245(1): 927-936.

[2] WANG J, XU F, JIN H, et al. Non-noble metal-based carbon 
composites in hydrogen evolution reaction: fundamentals to applications. Adv. Mater., 2017, 29(14): 1605838-1-35.

[3] GREELEY J, JARAMILLO T F, BONDE J, et al. Computational high-throughput screening of electrocatalytic materials for hydrogen evolution. Nat. Mater., 2006, 5(11): 909-913.

[4] LI D, BAYDOUN H, VERANI C N, et al. Efficient water oxidation using CoMnP nanoparticles. J. Am. Chem. Soc., 2016, 138(12): 4006-4009.

[5] MA T, DAI S, JARONIEC M, et al. Metal-organic framework derived hybrid $\mathrm{Co}_{3} \mathrm{O}_{4}$-carbon porous nanowire arrays as reversible oxygen evolution electrodes. J. Am. Chem. Soc, 2014, 136(39): 13925-13931.

[6] CHEN Y X, LAVACCHI A, MILLER H A, et al. Nanotechnology makes biomass electrolysis more energy efficient than water electrolysis. Nat. Commun., 2014, 5(6): 4036-1-7.

[7] CHEN S, DUAN J, VASILEFF A, et al. Size fractionation of two-dimensional sub-nanometer thin manganese dioxide crystals towards superior urea electrocatalytic conversion. Angew. Chem. Int. Ed., 2016, 55(11): 3804-3808.

[8] GWAK J, CHOUN M, LEE J. Alkaline ammonia electrolysis on electrodeposited platinum for controllable hydrogen production. ChemSusChem, 2016, 9(4): 403-408.

[9] BAMBAGIONI V, BEVILACQUA M, BIANCHINI C, et al. Self-sustainable production of hydrogen, chemicals, and energy from renewable alcohols by electrocatalysis. ChemSusChem, 2010, 3(7): 851-855.

[10] SRIVASTAVA M, DAS A K, KHANRA P, et al. Characterizations of in situ grown ceria nanoparticles on reduced graphene oxide as a catalyst for the electrooxidation of hydrazine. J. Mater. Chem. A, 2013, 1(34): 9792-9801.

[11] WANG H, MA Y, WANG R, et al. Liquid-liquid interface-mediated room-temperature synthesis of amorphous NiCo pompoms from ultrathin nanosheets with high catalytic activity for hydrazine oxidation. Chem. Commun, 2015, 51(17): 3570-3573.

[12] GAO W, LI C M, CHEN H, et al. Supported nickel-iron nanocomposites as a bifunctional catalyst towards hydrogen generation from $\mathrm{N}_{2} \mathrm{H}_{4} \cdot \mathrm{H}_{2} \mathrm{O}$. Green Chem., 2014, 16(3): 1560-1568.

[13] WEN X P, DAI H B, WU L S, et al. Electroless plating of Ni-B film as a binder-free highly efficient electrocatalyst for hydrazine oxidatio. Appl. Surf. Sci, 2017, 409: 132-139.

[14] JAKŠIĆ M M. Electrocatalysis of hydrogen evolution in the light of the Brewer-Engel theory for bonding in metals and intermetallic phases. Electrochim. Acta, 1984, 29(11): 1539-1550.

[15] WANG K C, XIA M, XIA T, et al. Metallurgically prepared NiCu alloys as cathode materials for hydrogen evolution reaction. Mat. Chem. Phys, 2017, 186(1): 61-66.

[16] YU L P, LEI T, NAN B, et al. Characteristics of a sintered porous $\mathrm{NiCu}$ alloy cathode for hydrogen production in a potassium hydroxide solution. Energy, 2016, 97: 498-505.
[17] 陈益宾, 张细华. 水热法合成纳米 $\mathrm{Ni}(\mathrm{OH})_{2}$. 化学工程与装备, 2012(10): 22-24.

[18] 方超, 庞驰, 赵文英. Mn-Ni-Al-Cu 系热敏陶瓷粉末的水热法处 理及其对电性能的影响. 中国陶瓷, 2019, 55(2): 39-43.

[19] LIU T, LIU D, QU F, et al. Enhanced electrocatalysis for energyefficient hydrogen production over $\mathrm{CoP}$ catalyst with nonelectroactive $\mathrm{Zn}$ as a promoter. Adv. Energy Mater, 2017, 7: 1700020$1-8$.

[20] WANG X L, ZHENG Y X, JIA M L, et al. Formation of nanoporous $\mathrm{NiCuP}$ amorphous alloy electrode by potentiostatic etching and its application for hydrazine oxidation. Int. J. Hydrogen Energy, 2016, 41(20): 8449-8458.

[21] ASNAVANDI M, SURYANTO B H R, YANG W F, et al. Dynamic hydrogen bubble templated $\mathrm{NiCu}$ phosphide electrodes for $\mathrm{pH}$ insensitive hydrogen evolution reactions. ACS Sustainable Chem. Eng., 2018, 6(3): 2866-2871.

[22] SUN Q Q, DONG Y J, WANG Z L, et al. Synergistic nanotubular copper-doped nickel catalysts for hydrogen evolution reactions. Small, 2018, 14(14): 1704137-1-9.

[23] LIU M, ZHANG R, ZHANG L, et al. Energy-efficient electrolytic hydrogen generation using a $\mathrm{Cu}_{3} \mathrm{P}$ nanoarray as a bifunctional catalyst for hydrazine oxidation and water reduction. Inorg. Chem. Front., 2017, 4: 420-423.

[24] TANG C, ZHANG R, LU W B, et al. Energy-saving electrolytic hydrogen generation: $\mathrm{Ni}_{2} \mathrm{P}$ nanoarray as a high-performance nonnoble-metal electrocatalyst. Angew. Chem. Int. Ed., 2017, 129(3): $860-864$.

[25] SHEN Y Q, DASTAFKAN K, SUN Q Q, et al. Improved electrochemical performance of nickelcobalt hydroxides by electrodeposition of interlayered reduced graphene oxide. Int. Energy. J. Hydrogen, 2019, 44(7): 3658-3667.

[26] GAO M R, LIANG J X, ZHENG Y R, et al. An efficient molybdenum disulfide/cobalt diselenide hybrid catalyst for electrochemical hydrogen generation. Nat. Commun., 2015, 6: 5982-1-7.

[27] SUN Q Q, ZHOU M, WANG L Y, et al. Hierarchical nanoporous $\mathrm{Ni}(\mathrm{Cu})$ alloy anchored on amorphous $\mathrm{NiFeP}$ as efficient bifunctional electrocatalysts for hydrogen evolution and hydrazine oxidation. J. Catal., 2019, 373: 180-189.

[28] WANG L Y, LI Y B, SUN Q Q, et al. Ultralow Fe(III) ion doping triggered generation of $\mathrm{Ni}_{3} \mathrm{~S}_{2}$ ultrathin nanosheet for enhanced oxygen evolution reaction. ChemCatChem, 2019, 11: 2011-2016.

[29] SUN Y F, GAO S, LEI F C, et al. Atomically-thin two-dimensional sheets for understanding active sites in catalysis. Chem. Soc. Rev., 2015, 44(3): 623-636.

[30] YUE X Z, YI S S, WANG R W, et al. A novel and highly efficient earth-abundant $\mathrm{Cu}_{3} \mathrm{P}$ with $\mathrm{TiO}_{2}$ "P-N" heterojunction nanophotocatalyst for hydrogen evolution from water. Nanoscale, 2016, 8(40): 17516-17523. 


\title{
补充材料:
}

\section{水热合成镍铜复合磷化物及其电催化析氢与肼氧化性能}

\author{
李 兆 ${ }^{1}$, 孙强强 ${ }^{2}$, 陈索倩 ${ }^{2}$, 周春生 ${ }^{2}$, 曹 静 $^{1}$, 王永锋 ${ }^{1}$, 王亚楠 ${ }^{1}$
}

(1. 西安航空学院材料工程学院, 西安 710077; 2. 商洛学院 陕西省尾矿资源综合利用重点实验室, 商洛 726000)

\section{S1 镍铜比对 $\mathrm{NiCuP/NM}$ 电催化剂表 观形貌的影响}

为了增加表面粗楉度, 获得更大的催化活性面 积, 控制水热温度 $120{ }^{\circ} \mathrm{C}$, 保温时间 $24 \mathrm{~h}$, 掺磷浓 度 $20 \mathrm{mmol} \cdot \mathrm{L}^{-1}, \mathrm{CuSO}_{4}$ 浓度为 $1 \mathrm{mmol} \cdot \mathrm{L}^{-1}$, 研究镍 铜摩尔比 $(2: 1 、 4: 1 、 6: 1 、 8: 1 、 10: 1)$ 对所得电 极材料表观形貌的影响, 相应的 SEM 照片见图 S1。

由图 1 可知, 随着镍配比的不断增大, 镍网表 面形成球形颗粒的尺寸逐渐减小, 且球形颗粒表面 逐渐形成纳米尺寸的线毛结构。分析认为, 中间产 物亚磷酸碱式盐使得镍网表面形成尺寸不一的球形 颗粒结构 ${ }^{[1]}$, 进一步反应后, 形成多孔纳米片状结 构的磷化镍, 便在球形颗粒表面构筑纳米尺寸的线 毛结构。当镍铜配比为 8:1 时, 电极表面获得的球 状结构尺寸均匀, 且表层覆盖大量纳米尺寸线毛结
构, 大幅增加了材料表面的粗粘度, 有利于后续电 催化过程; 镍浓度进一步增大时, 物料增加而纳米 结构未有显著变化, 故镍铜配比以 $8: 1$ 为宜。

\section{S2 掺磷浓度对 $\mathrm{NiCuP/NM}$ 电催化剂 表观形貌的影响}

为探究掺磷浓度对产物形貌的影响, 控制水热温 度 $120{ }^{\circ} \mathrm{C}$, 保温时间 $24 \mathrm{~h}$, 镍铜配比 $8: 1$, 以 FESEM 作为表征手段, 测定不同掺磷浓度 $(10 、 20 、 30$ 、 $40 \mathrm{mmol} \cdot \mathrm{L}^{-1}$ ) 条件所得产物的表观形貌, 如图 S2 所示。

由图 2 可知, 镍网表面的镍铜磷复合电催化剂 均由球形颗粒堆积而成, 随掺磷浓度的增大, 球形 颗粒的尺寸逐渐增大, 颗粒表面逐步形成纳米尺寸 的线毛结构, 后又变得光滑平整。分析认为, 镍铜磷 化物的形成促使颗粒表面出现纳米晶, 随掺磷量的 持续增大, 纳米晶通过 Ostwald 熟化效应 ${ }^{[2]}$ 快速生
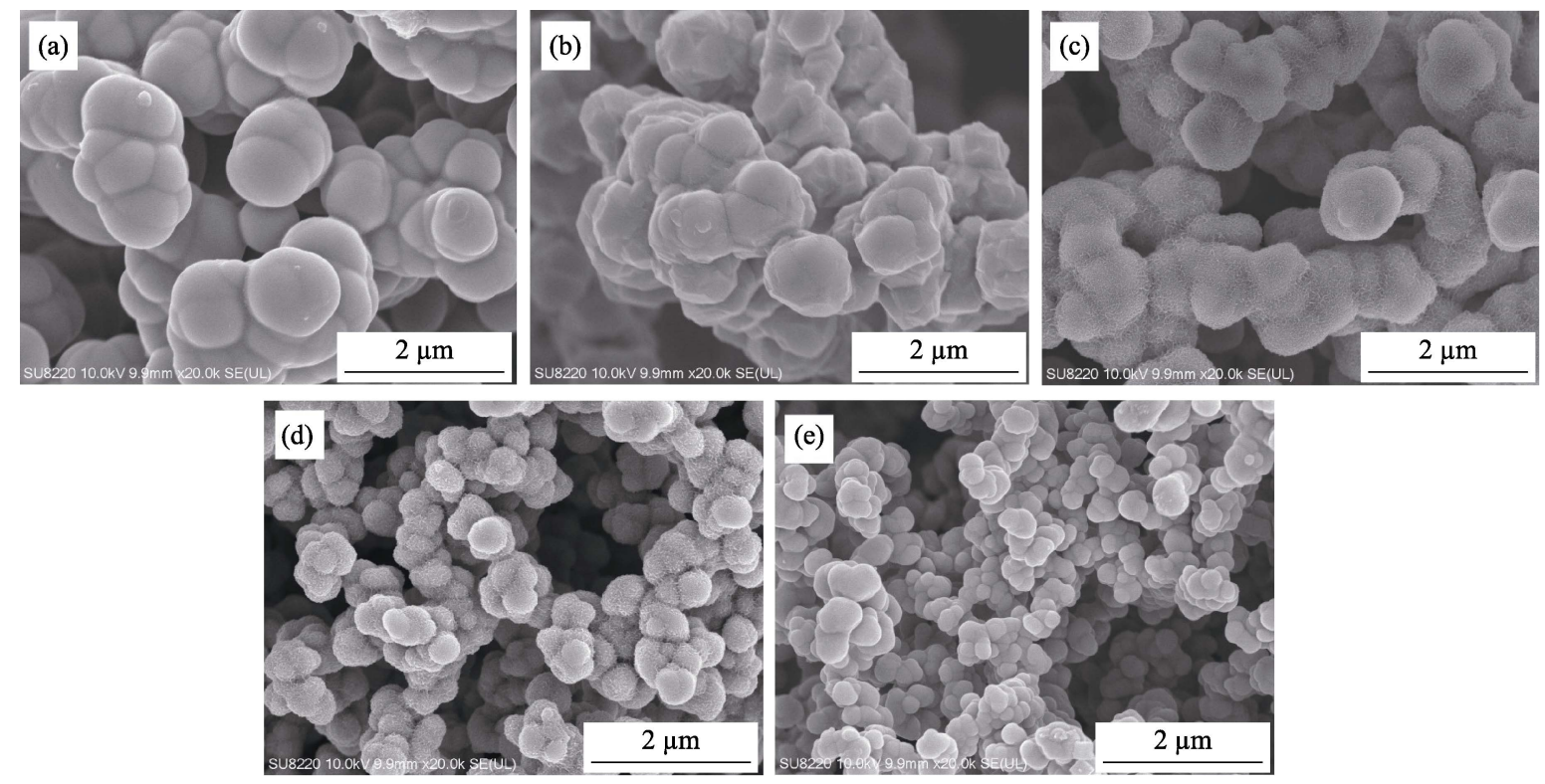

图 S1 不同镍铜比制得的复合电催化剂的 SEM 照片

Fig. S1 SEM images of composite electrocatalysts with different ratios of $\mathrm{Ni}$ to $\mathrm{Cu}$ (a) $2: 1$; (b) $4: 1$; (c) $6: 1 ;$ (d) $8: 1$; (e) $10: 1$ 

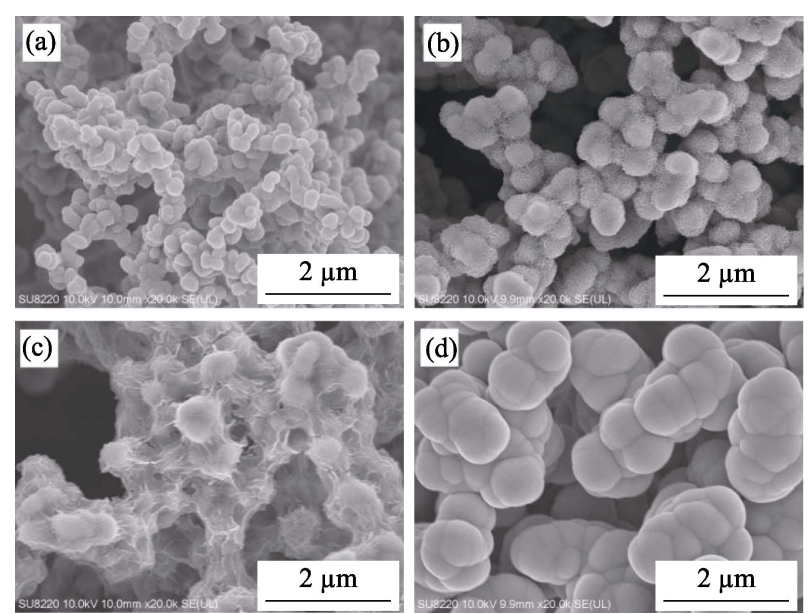

图 S2 不同掺磷浓度所得复合电催化剂的 SEM 照片

Fig. S2 SEM images of composite electrocatalysts prepared by different $\mathrm{P}$ doping concentrations

(a) $10 \mathrm{mmol} \cdot \mathrm{L}^{-1}$; (b) $20 \mathrm{mmol} \cdot \mathrm{L}^{-1}$; (c) $30 \mathrm{mmol} \cdot \mathrm{L}^{-1}$; (d) $40 \mathrm{mmol} \cdot \mathrm{L}^{-1}$

长, 逐渐演变成球形颗粒聚集的胞体结构。当掺磷 浓度为 $20 \mathrm{mmol} \cdot \mathrm{L}^{-1}$ 时, 电极表面形成了平均尺寸 为 $400 \mathrm{~nm}$ 的球形颗粒, 表面密集覆盖着由镍铜磷化 物纳米晶所构成的线毛结构, 给后续电催化反应提 供充足的反应空间。随着浓度的持续增大，纳米结 构反而逐渐消失。因而, 复合电催化剂的制备选择 掺磷浓度 $20 \mathrm{mmol} \cdot \mathrm{L}^{-1}$ 为宜。

\section{S3 水热温度对 $\mathrm{NiCuP/NM}$ 电催化剂 表观形貌的影响}

为研究水热温度对产物表观形貌的影响，控制
反应物配比 $(\mathrm{Ni}: \mathrm{Cu}: \mathrm{P}$ 摩尔比为 $8: 1: 20)$ 和反应时 间 $24 \mathrm{~h}$, 分别测定水热温度为 $100 、 120 、 140 、 160$ 、 $180{ }^{\circ} \mathrm{C}$ 下所得镍铜磷复合电催化剂的 SEM 照片, 结果如图 S3 所示。

由图 3 可知, 水热温度由 $100{ }^{\circ} \mathrm{C}$ 升高时, 构成 复合电催化剂的球形颗粒尺寸减小，分散性增强。 $140{ }^{\circ} \mathrm{C}$ 时, 球状结构分布均匀且表层形成纳米尺度 的线毛结构; 当水热温度持续升高时，球形颗粒表 面的线毛结构逐渐消失，反而团聚凝结成杂乱、无 规则、尺寸不一的块体状结构。分析认为, 一定范 围内温度升高，使得晶体成核速率大幅提高，在镍 网表面便形成更为分散、数量更多的复合金属磷化 物晶核，晶体长大后在表面生成纳米尺寸的线毛球 状结构; 温度过高时, 晶体的形核及生长速率过快, 长大后的晶体反而聚集在一起形成大小不一的颗粒 团聚体。为了在电催化应用中暴露更大的活性面积, 催化剂制备过程优选的水热温度为 $140{ }^{\circ} \mathrm{C}$ 。

\section{S4 保温时间对 $\mathrm{NiCuP/NM}$ 电催化剂 表观形貌的影响}

保温时间可以直接影响溶液中离子的吸附、分 解、脱附过程 ${ }^{[3]}$ 以及晶体的生长过程, 为探究保温时 间对电催化剂表观形貌的影响，选择物料配比 $(\mathrm{Ni}: \mathrm{Cu}: \mathrm{P}$ 摩尔比为 $8: 1: 20)$, 反应温度 $140{ }^{\circ} \mathrm{C}$, 研究了保温时间为 $12 、 18 、 24 、 30 \mathrm{~h}$ 时所得产物的 表观形貌，结果见图 4。
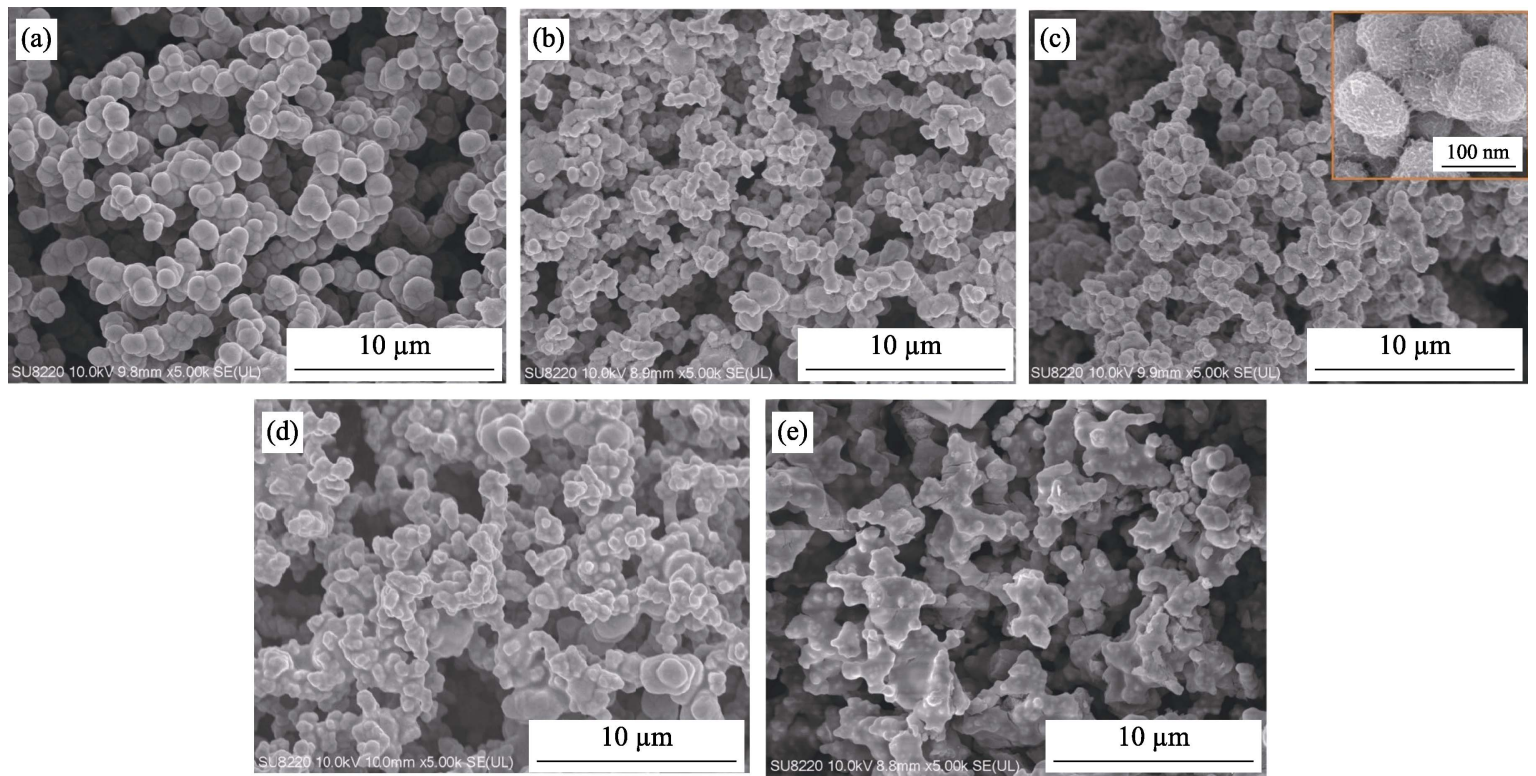

图 S3 不同水热温度制得的复合电催化剂的 SEM 照片

Fig. S3 SEM images of composite electrocatalysts prepared at different hydrothermal temperatures (a) $100{ }^{\circ} \mathrm{C}$; (b) $120{ }^{\circ} \mathrm{C}$; (c) $140{ }^{\circ} \mathrm{C}$; (d) $160{ }^{\circ} \mathrm{C}$; (e) $180{ }^{\circ} \mathrm{C}$ 

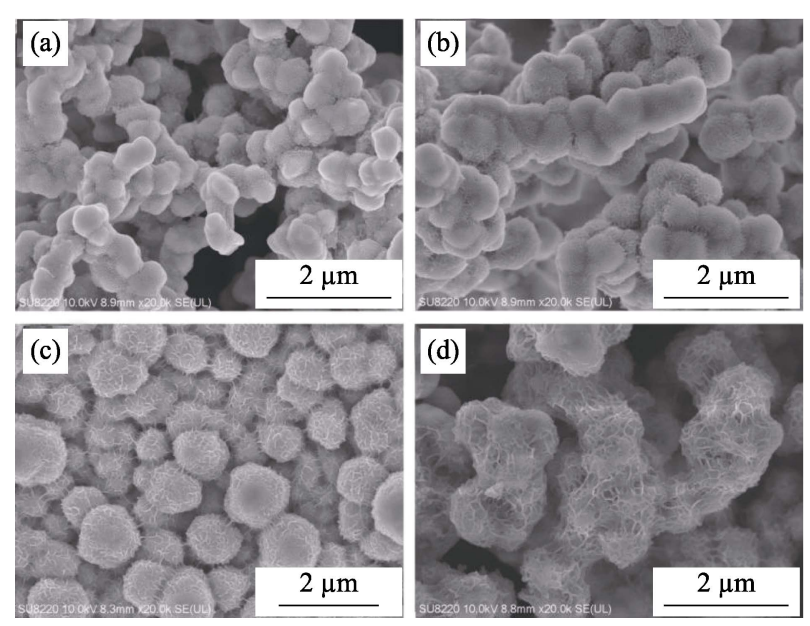

图 S4 不同保温时间制得的复合电催化剂的 SEM 照片

Fig. S4 SEM images of composite electrocatalysts prepared with different hydrothermal time

(a) $12 \mathrm{~h}$; (b) $18 \mathrm{~h}$; (c) $24 \mathrm{~h}$; (d) $30 \mathrm{~h}$

由图可知, 保温 $12 \mathrm{~h}$ 时, 亚磷酸盐球形颗粒的 表面便形成了纳米结构的复合磷化物。当保温时间
延长至 $24 \mathrm{~h}$ 时, 催化剂球状结构的直径更大，且表 层纳米尺度的线毛结构也越发密集, 这是因为随着 保温时间的延长, 晶粒尺寸逐渐增大, 同时球形颗 粒表面产生的复合磷化物也越来越多。当保温时间 延长至 $30 \mathrm{~h}$ 时, 催化剂表面密集覆盖了纳米尺寸的 线毛结构, 但因为 Ostwald 熟化效应, 晶体过度生 长使得大尺寸的球形颗粒团聚凝结，微纳结构反而 不如预期。因此, 镍铜复合磷化物水热合成最优的 保温时间为 $24 \mathrm{~h}$ 。

\section{参考文献:}

[1] 征景森, 张闯, 曹飞, 等. 磷化镍微纳米材料的水热合成与表征. 化学世界, 2016(6): 351-355.

[2] LIU S L, QIAN Y T, XU L Q. Synthesis and characterization of hollow spherical copper phosphide $\left(\mathrm{Cu}_{3} \mathrm{P}\right)$ nanopowders. Solid State Commun., 2009, 149(11/12): 438-440.

[3] 张立德, 牟季美. 纳米材料与纳米结构. 北京: 科学出版社, 2002: 133-165. 